\title{
The Degree to Which the Activities Guide Includes Life Skills and Their Acquisition by High School Students
}

\author{
Nasser Ahmad Al-Khawaldeh, Amani Odeh Matar*, Hussam N. Fakhouri \\ School of Educational Sciences, University of Jordan, Amman, Jordan
}

Received February 19, 2021; Revised March 11, 2021; Accepted April 22, 2021

\section{Cite This Paper in the following Citation Styles}

(a): [1] Nasser Ahmad Al-Khawaldeh, Amani Odeh Matar, Hussam N. Fakhouri, "The Degree to Which the Activities Guide Includes Life Skills and Their Acquisition by High School Students," Universal Journal of Educational Research, Vol. 9, No. 5, pp. 1088 - 1095, 2021. DOI: 10.13189/ujer.2021.090522.

(b): Nasser Ahmad Al-Khawaldeh, Amani Odeh Matar, Hussam N. Fakhouri (2021). The Degree to Which the Activities Guide Includes Life Skills and Their Acquisition by High School Students. Universal Journal of Educational Research, 9(5), 1088 - 1095. DOI: 10.13189/ujer.2021.090522.

Copyright $\bigcirc 2021$ by authors, all rights reserved. Authors agree that this article remains permanently open access under the terms of the Creative Commons Attribution License 4.0 International License

\begin{abstract}
This study aims to investigate the degree to which the activities guide includes life skills subject and their acquisition by high school students. To achieve the goal of this study, first of all, a questionnaire consisting of (24) paragraphs has been developed and distributed to high school students with sample of (150) students in Madaba Latin schools. Secondly, a content analysis has been performed for the activities guide that has been thought in the school titled "interactive curriculum for activity classes" and a second instrument has been developed too for the analysis of the content. The researchers used the descriptive survey method. The study results show that the degree of inclusion of life skills subject in the activities guide "interactive curriculum for activity classes" was low, and concerning the degree of high school students' acquisition of life skills, the results show that the degree of high school students acquiring life skills available in the guide has an average of (2.95\%). Based on the results of the study, we recommend using the study results to review the guide "the interactive curriculum for activity classes" and to consider life skills a priority in it.
\end{abstract}

Keywords Life Skills, Interactive Curriculum, High School Students

\section{Introduction}

School activities are a driving force that must be incorporated into the learning and teaching process; By achieving effective students, they will have a sense of pride, a sense of self-importance at the national and global level, in addition to their belief that every success achieved on this changing world is linked to the students 'ability to learn, and they will be considered qualified because they are teachers of the future who can translate what they have learned both in school and in their life which is constantly changing.

Depending on the constructivism of Jordanian curricula on the outcomes and criteria, and its emphasis on interactive dialogue, and the meaningful and enjoyable debate that exists between the teacher and the learner to engage, deepen the research, and exchange ideas and experiences; That pushes the student to ask, confront problems related to it, and look at it in another perspective. The Ministry of Education found that activities, in general, are concerned with developing the skills, values, and capabilities of the student within the applied practical context based on theoretical and practical understanding, and balance between in-depth and expansion of content and its organization around several ideas and principles that are based on the student's previous learning, and their capabilities to rebuild it to achieve his personality [11].

Activities have an important role that revolves around transforming students' convictions from mastery of information and data to making these data a basis for mastery of knowledge. It includes skills and values, intending to build a balanced personality of students who enjoy comprehensive, renewable, and comprehensive 
competencies, and which have skills (thinking, creativity, and higher thinking), within a framework of supportive values that enable students have the knowledge and skills to solve their life problems in appropriate ways out of the box. Therefore, the concept of school activities, in general, is complex. Activities that develop students' inclinations and desires overlap with activities related to the curriculum and practical teaching methods, in addition to activities based on linking life concepts to the subjects. That works to stabilize the values according to the national and global dimensions [5].

The activities guide dealt with the "interactive curriculum for activity classes", on four main axes distributed over 72 activities: (thinking skills, environment, and work, civil values, and ideals, technical and beauty taste), as it covered the axes of values and civil ideals, and thinking skills, activities of the guide in the form of whole; Having examined several values, and the role of the teacher in it is directed and facilitated, and to stimulate dialogue about the content of these activities; In easy ways to provide students with skills from multiple levels, in addition to the skill of creativity. As for the themes of the environment and work, artistic taste, and beauty, they are covered less in the activities guide, as they must be achieved through the existing dialogue between the teacher and the learner, or by offering examples that help clarify and deepen understanding.

Based on the foregoing, it is the responsibility of the teacher based on the implementation of the content of the activities guide, the function of notifying the activity closest to the level of development for the students of the class, and pre-planning it, and determining additional products and contents for each activity, in addition to the procedures and strategies that are followed in implementing these activities, in a way It brings benefit and enjoyment. Teachers wishing to give a guide to activities, who are discharged to perform this task, regardless of their specialties and provided with training by a committee of educational supervisors; As field trainers, to be able to train teachers, and ensure their performance competencies; To achieve the activities of the guide before its actual implementation [12].

It is the life skills and abilities (mental, sensory, and emotional) that help the student to face problems and the ability to solve them. It has been defined by the United Nations International Children's Emergency Fund (UNICEF) as the necessary social and psychological capabilities for positive adaptive behaviors; That enables the student to deal with life challenges effectively and confidently and has been classified into 3 categories (personal communication and effective communication skills, personal skills based on character development and strengthening, ability to self-management, and cognitive skills to analyze and understand the information in greater depth) (UNICEF, 2009).

The World Health Organization (WHO) has included ten life skills which are (problem-solving, critical thinking, decision making, creative thinking, communication and communication, self-awareness, personal relationships, emotion management, emotion clamping, and stress management), as they form the first stage from the age of students, a golden opportunity to acquire these skills to meet the challenges of daily life with high skill, when these stages of students offer various educational experiences, in many of his life situations, and enable him to respond to the rapid changes and developments of the age [8] [15].

Based on the degree of interest of the Ministry of Education in life skills, it came up with the adoption of a draft activities guide, "the interactive curriculum for activity classes" to contribute to giving students an opportunity to develop their life skills, and confirm themselves with the educational development plan based on comprehensive quality standards, knowledge economy, and in view of the importance of a guide activities in preparing students, tending their attitudes toward positivity, belonging to the school consciously, and firmly with the values, and civic ideals of their personalities. And that is through the compatibility between the learning content and its various sources, and considering activities an important part of it, and that learning has not and will not be complete except with theoretical and practical work related to the content of the study material, which is carried out inside or outside the school facilities through the practical nature of the dialogue, and performance by paying attention to the characteristics of the brainstorming meeting, which helps to develop thinking skills, creativity in a realistic way, and the involvement of students in self-evaluation of their interaction, and the mood of this interaction [16][17].

Accordingly, the study problem was to determine the degree to which the activities guide includes an "interactive curriculum for activity classes" of life skills and students' acquisition of them, which are represented by the following two questions:

- What is the degree of inclusion life skills in the activity guide of the interactive curriculum in Jordan?

- What is the degree of high school students' acquisition of life skills that are available in the activities guide "interactive curriculum for activity classes"?

\section{Related Work}

Abu Saiba, Al-Hadidi (2018) study aimed to identify the degree of availability of life skills included in the English language textbook for the sixth grade in Amman and the degree of students' acquisition of it from the viewpoint of their teachers. The study community and its sample consisted of all pages of the English language book was also chosen by the English language teachers from three districts of the capital, Amman, by the stratified random method. They numbered (322) male and female teachers. The researchers prepared two tools of study (a form, content analysis) distributed over three main areas: mental, 
manual (scientific), and social skills. The study results were that the degree of availability of life skills included in the English language book for the sixth grade appeared with a high degree in the field of mental skills by a percentage (45\%), and the degree of students' acquisition of life skills came from the viewpoint of their teachers with an average degree and on all three fields of study and the absence of differences according to gender and qualification variables Scientific, level of experience, excluding the gender variable in the area of social skills and favor of females.

Al-Jazi, Al-Rusaei, Saleh, Al-Hallilat's (2016) study, aimed to know the degree of including life skills in science books for the first three grades in Jordan, where the descriptive approach was used with a content analysis card where a list of life skills that were required to be included in the targeted books was included; included Based on (63) sub-skills, the study concluded that the total number of repetitions of life skills in science books amounted to (764) repeats distributed over seven major life skills, and mental skills were the most repetitive skills received by $(17.93 \%)$, while health and food skills were received Preventive and environmental skills are to a low degree, while emotional skills are not included at all.

Abboud's (2016) study aimed to analyze the life skills included in the books of social studies for the high stage in Jordan prescribed by the Jordanian Ministry of Education for the academic year 2015/2016 AD and included five study books, the descriptive analytical approach was used by developing a content analysis tool to identify the life skills included in the books that included four dimensions of life skills, which are: After intellectual and scientific skills, and sub-skills (37) subdivided them, and the result of the study focused on environmental life skills for the needs of students in the high stage for it and the emergence of a lack of focusing on some of them.

Sarmad, Habiby, and Arvantan (2012) conducted a study aimed to investigate life skills in basic science textbooks, the descriptive analytical approach was used through the content analysis card. The results indicated that thinking skills (analytical and creative) were the most frequent $(17,55 \%)$, and basic skills ranked last with the lowest frequency $(1.69 \%)$.

Eteokleous (2011) conducted a study aimed to know the extent of assessing the social studies curriculum and its effect on developing social skills in Cyprus, and used the descriptive survey method by distributing the questionnaire tool to a sample of (303) students, and the results showed that the social studies curriculum has a major role in developing the social skills of students.

\section{Methods and Instruments}

\subsection{Study Design and Participants}

We conducted across-sectional study and the researchers developed two study instruments, the questionnaire, and the content analysis; the first instrument has been applied to high school students in Madaba Latin Schools who were studying during the semester of the year 2019/2020. The number of the sample is (1239) male and female students according to the statistics of the Latin schools. (150) male and female students from the high stage in Deir Al-Latin schools were selected, based on the random stratified sample according to the random sample table for a known population. We also used a descriptive and analytical approach to answer the first question of the study, whereas the second instrument is content analysis that has been performed by the authors.

\subsection{The Survey Instrument and Related Measures}

The instrument was developed by referring to theoretical literature and previous studies with the aim of developing the study instrument in its initial form to know the degree to which the activities guide includes an "interactive curriculum for activity classes" for life skills and students' acquisition of them, as the instrument's paragraphs reached (24) paragraphs, and they were designed based on Likert scale) Five-dimensional, the paragraphs were constructed in a positive direction, and weights were given to the paragraphs as follows: strongly agreed five degrees, agreed: four degrees, somewhat agree: three degrees, disagree: two degrees, strongly disagree: one degree.

The content analysis is the second study instrument, which was used after reviewing previous researches and studies related to the subject of the study and to reach the goals of the study to monitor life skills that can be included in the activities guide, which is one of the most used instruments in the analysis of education curricula, it is an analysis instrument, a description in general, the content is approved as a unit of analysis.

The instrument's content validity was confirmed by using face validity by presenting it to a group of arbitrators, from faculty experience and specialization members in Jordanian universities to express their observations in terms of determining the degree of appropriateness of the paragraphs and their comprehensiveness to measure the area in which those paragraphs were mentioned, and the degree of the affiliation of these paragraphs to the field in which they were mentioned, the degree of clarity of the paragraphs, their linguistic and grammatical integrity, and the statement of the proposed amendments to the paragraphs, (80\%) of the arbitrators' observations are adopted in general, without neglecting to make the proposed amendments to an amendment in the linguistic formulation of the paragraphs, after which an instrument was produced the study is in its final form.

The stability of the analysis was verified by using the method of stability over time, using it to analyze the content of the activities guide, through the researchers analyzing a random sample of the content of the activities 
guide, "the interactive curriculum of activity classes ", and then the researchers analyzed it again after the first analysis process and with a time limit (21) Days, and then the stability coefficient was calculated according to the following H.listi equation:

Stabilitycoefficient $=\% 100 *$ numberof timesagreedbetween firstandsecondanalysis Thenumberoftimestheagreement + thedifferencetimes

The stability coefficient has reached (90.2), and this is a percentage that can be assured.

\subsection{Data Analyses}

Statistical treatments for data were performed in this study using the Statistical Package for Social Sciences (SPSS). We calculated the frequency, percentages, and standard deviations for life skills included in the activities guide "Interactive curriculum for activity classes" in Jordan. We also calculated the Arithmetic Averages and Standard deviations to measure the point that the activities guide "interactive curricula for activities classes" in Jordan for life skills.

\section{Results and Discussion}

This section presents the results and the discussion of the results. However, to explain the study aim, the iterations and percentages were calculated to know the degree to which the activities guide includes the life skills in the "interactive curriculum of activity classes" in Jordan, as shown in Table 1.

Table 1. Frequencies, percentages, and standard deviations for life skills included in the activities guide "Interactive curriculum for activity classes" in Jordan are listed in descending order.

\begin{tabular}{|c|c|c|c|c|c|}
\hline The number & Life Skills & Frequency & Percentage & Rank & Rating \\
\hline 11 & Communication skills & 9 & $7 \%$ & 1 & High \\
\hline 16 & Creative thinking & 7 & $5 \%$ & 2 & High \\
\hline 33 & Respect for the opinion of others & 7 & $5 \%$ & 2 & High \\
\hline 8 & Teamwork & 5 & $4 \%$ & 4 & High \\
\hline 9 & Advance planning & 5 & $4 \%$ & 4 & High \\
\hline 1 & Self-expression & 4 & $3 \%$ & 6 & High \\
\hline 4 & Consolidating social values & 4 & $3 \%$ & 6 & High \\
\hline 24 & Observation & 4 & $3 \%$ & 6 & High \\
\hline 41 & Automatic expression & 4 & $3 \%$ & 6 & High \\
\hline 45 & Creative imagination & 4 & $3 \%$ & 6 & High \\
\hline 12 & Accept the difference & 3 & $2 \%$ & 11 & High \\
\hline 18 & Collaborative work & 3 & $2 \%$ & 11 & High \\
\hline 19 & Multiple solutions to the problem & 3 & $2 \%$ & 11 & High \\
\hline 21 & Problem Solving & 3 & $2 \%$ & 11 & High \\
\hline 23 & Accept criticism & 3 & $2 \%$ & 11 & High \\
\hline 26 & The importance of change in life & 3 & $2 \%$ & 11 & High \\
\hline 30 & Time management & 3 & $2 \%$ & 11 & High \\
\hline 37 & Renouncing violence and extremism & 3 & $2 \%$ & 11 & High \\
\hline 59 & Justice & 3 & $2 \%$ & 11 & High \\
\hline 5 & Self-assurance & 2 & $2 \%$ & 20 & Average \\
\hline 7 & Successful leadership & 2 & $2 \%$ & 20 & Average \\
\hline 10 & Teamwork & 2 & $2 \%$ & 20 & Average \\
\hline 39 & Analytical thinking & 2 & $2 \%$ & 20 & Average \\
\hline 43 & Take responsibility & 2 & $2 \%$ & 20 & Average \\
\hline 50 & Team play & 2 & $2 \%$ & 20 & Average \\
\hline 51 & Expression by body language & 2 & $2 \%$ & 20 & Average \\
\hline 56 & The conclusion & 2 & $2 \%$ & 20 & Average \\
\hline 57 & Exchange of experiences & 2 & $2 \%$ & 20 & Average \\
\hline 2 & Establishing social relations & 1 & $1 \%$ & 29 & Low \\
\hline
\end{tabular}


Table 1 Continued

\begin{tabular}{|c|c|c|c|c|c|}
\hline 3 & Tolerance & 1 & $1 \%$ & 29 & Low \\
\hline 6 & Knowledge of desired behaviors & 1 & $1 \%$ & 29 & Low \\
\hline 13 & Make comparisons & 1 & $1 \%$ & 29 & Low \\
\hline 14 & Honest positive competition & 1 & $1 \%$ & 29 & Low \\
\hline 15 & The importance of group decision & 1 & $1 \%$ & 29 & Low \\
\hline 17 & Credibility of information & 1 & $1 \%$ & 29 & Low \\
\hline 20 & Coordination of group work & 1 & $1 \%$ & 29 & Low \\
\hline 22 & Perseverance and not giving up & 1 & $1 \%$ & 29 & Low \\
\hline 25 & $\begin{array}{c}\text { Differentiate between description and } \\
\text { judgment }\end{array}$ & 1 & $1 \%$ & 29 & Low \\
\hline 27 & Deny the unconfirmed assumptions & 1 & $1 \%$ & 29 & Low \\
\hline 28 & Self-development & 1 & $1 \%$ & 29 & Low \\
\hline 29 & Social Intelligence & 1 & $1 \%$ & 29 & Low \\
\hline 31 & Do not hesitate & 1 & $1 \%$ & 29 & Low \\
\hline 32 & Self-affirmation & 1 & $1 \%$ & 29 & Low \\
\hline 34 & respecting others & 1 & $1 \%$ & 29 & Low \\
\hline 35 & The importance of creativity in life & 1 & $1 \%$ & 29 & Low \\
\hline 36 & Etiquette of eating & 1 & $1 \%$ & 29 & Low \\
\hline 38 & role play & 1 & $1 \%$ & 29 & Low \\
\hline 40 & Dialogue with others & 1 & $1 \%$ & 29 & Low \\
\hline 42 & Humility & 1 & $1 \%$ & 29 & Low \\
\hline 44 & changing the tone of your voice & 1 & $1 \%$ & 29 & Low \\
\hline 46 & Focus and attention & 1 & $1 \%$ & 29 & Low \\
\hline 47 & Listen up & 1 & $1 \%$ & 29 & Low \\
\hline 48 & $\begin{array}{l}\text { The difference between a person's } \\
\text { perceptions of himself and others' } \\
\text { perceptions of him }\end{array}$ & 1 & $1 \%$ & 29 & Low \\
\hline 49 & Know the rights granted to me & 1 & $1 \%$ & 29 & Low \\
\hline 52 & Know the rights of others & 1 & $1 \%$ & 29 & Low \\
\hline 53 & $\begin{array}{c}\text { Determine the standard of rights } \\
\text { arrangement }\end{array}$ & 1 & $1 \%$ & 29 & Low \\
\hline 54 & Rationale for prioritizing rights & 1 & $1 \%$ & 29 & Low \\
\hline 55 & Influential role model & 1 & $1 \%$ & 29 & Low \\
\hline 58 & Appreciation of peace and stability & 1 & $1 \%$ & 29 & Low \\
\hline 60 & Reality Orientation & 1 & $1 \%$ & 29 & Low \\
\hline 61 & The investigation & 1 & $1 \%$ & 29 & Low \\
\hline 62 & Organized thought & 1 & $1 \%$ & 29 & Low \\
\hline 63 & Collaborative work & 1 & $1 \%$ & 29 & Low \\
\hline 11 & & 133 & $100 \%$ & & Total \\
\hline
\end{tabular}

Table 1 shows that it's obvious that the degree of inclusion of life skills in the activities guide "interactive curriculum for activity classes" was low, so the percentages ranged between $(7 \%$ to $1 \%)$, and this may be due to the fact that, given the number of life skills, we note that much greater than the number of classes that cover these skills in the activities guide; then the focus was on quantity rather than quality, so life skills are accumulated in the activities guide for the time allocated to teaching, which causes students to resort to memorization and retrieval to absorb the skills without understanding them, which makes them feel frustrated sometimes, which may prompt them to drop out of the ration.

This may be attributed to the authors of the activities 'belief in the importance of the skill of effective communication that achieves the highest levels of human interaction by investing all the capabilities of receiving and throwing by using the means and media that suit the student's situation in its spatial and temporal dimensions, to express feelings and needs in a smooth and simple way so that both parties can absorb the message accept all statements and deeds from the other party for the purpose for which this communication came.

This may be attributed to the awareness of the authors of 
the activities guide, the importance of including the skill of structured thinking, investigation, focus, and attention of the student as a case of purposeful thinking that depends on an organized intellectual sequence that aims to enhance the student's knowledge to collect accurate, arranged and honest information, but these skills have a low degree of lack. It is contained in the activities guide, except in one activity, despite the importance of these skills in the student's understanding of daily life, as the importance of organized thinking, investigation, focus, and attention varies in various fields, which makes the student acquire a weapon when facing problems to know the student the skills that must be used, and the method that achieve an appropriate solution.

Second question: What is the degree of high school students acquiring the life skills that are available in the activities guide "interactive curriculum for activity classes"?

To answer this question, arithmetic averages and standard deviations were calculated to know the degree of high stage students' acquisition of life skills available in the activities guide "Interactive Curriculum for Activity Classes" in Jordan, and Table 2 shows that.

Table 2 results show that to know the degree of high school students acquiring the life skills available in the activities guide, "the interactive curriculum for activity classes" in Jordan was a medium degree, so the arithmetic averages ranged between (4.44 to 1.62), and with regard to the overall degree was medium, This is due to the mean of the arithmetic average of (2.95), and this may be due to the students 'belief that the teacher based on the activity cannot activate it in a manner that ensures the achievement of all the skills mentioned in the activities guide, due to the large number of life skills mentioned in the activities guide, and the lack of training of the responsible teacher on Activity classes for dealing with students in a practical and theoretical way enjoyable, stimulating and feasible to achieve the desired goal of activity classes, and accordingly, a good focus must be placed on the integration between the results of the activities of the guide and the goals of other subjects in a manner that ensures a balanced growth of the personality of the students.

Table 2. Arithmetic Averages and Standard deviations to the point that the activities guide "interactive curricula for activities classes" in Jordan for life skills, they are listed in descending order

\begin{tabular}{|c|c|c|c|c|c|}
\hline $\begin{array}{l}\text { Paragraph } \\
\text { Number }\end{array}$ & The paragraph & Arithmetic mean & $\begin{array}{l}\text { Standard } \\
\text { Deviation }\end{array}$ & Rank & Rating \\
\hline 3 & freedom of expression & 4.44 & .573 & 1 & High \\
\hline 13 & $\begin{array}{c}\text { Participation in collective } \\
\text { decision-making }\end{array}$ & 4.35 & .645 & 2 & High \\
\hline 20 & Self-reliance & 4.20 & .695 & 3 & High \\
\hline 9 & Self-assurance & 4.14 & .695 & 4 & High \\
\hline 4 & Know the rights granted to me & 4.12 & .655 & 5 & High \\
\hline 1 & Respect for the opinion of others & 3.95 & .842 & 6 & High \\
\hline 5 & Time management & 3.93 & .895 & 7 & High \\
\hline 11 & The ability to make decisions & 3.70 & .588 & 8 & High \\
\hline 7 & Know the rights of others & 3.31 & 1.055 & 9 & Average \\
\hline 2 & Listening & 3.22 & .664 & 10 & Average \\
\hline 23 & Accept criticism & 2.80 & 1.221 & 11 & Average \\
\hline 15 & Initiative & 2.73 & 1.085 & 12 & Average \\
\hline 18 & Take responsibility & 2.67 & 1.066 & 13 & Average \\
\hline 6 & Tolerance & 2.61 & .918 & 14 & Average \\
\hline 21 & $\begin{array}{l}\text { Refuse the unacceptable social } \\
\text { postulates }\end{array}$ & 2.51 & 1.230 & 15 & Average \\
\hline 16 & The pursuit of self-development & 2.32 & .999 & 16 & Low \\
\hline 12 & $\begin{array}{c}\text { Implement the decision and bear its } \\
\text { results }\end{array}$ & 2.31 & 1.322 & 17 & Low \\
\hline 17 & Passive adjustment & 2.26 & 1.234 & 18 & Low \\
\hline 19 & Attention to personal cleanliness & 2.12 & .874 & 19 & Low \\
\hline 22 & Attention to clean environment & 1.89 & .796 & 20 & Low \\
\hline 8 & Etiquette of permission & 1.85 & 679 & 21 & Low \\
\hline 10 & Preserve personal property & 1.85 & .673 & 22 & Low \\
\hline 14 & $\begin{array}{l}\text { Give sufficient time for the } \\
\text { decision-making process }\end{array}$ & 1.84 & .920 & 23 & Low \\
\hline 24 & Volunteer work & 1.62 & .620 & 24 & Low \\
\hline Total & freedom of expression & 2,95 & 20.944 & & Average \\
\hline
\end{tabular}


This may be due to the awareness of those responsible for developing the Activity Manual of the importance of developing the freedom of expression skill of students; To be able to express their thoughts and opinions through speech, writing, or any other way, is the basis for the democratic system of the state, provided that the restrictions and procedures of freedom of expression that students learn through lessons of activity are taught by the teacher; To regulate the use of freedom, and to preserve national laws, people's rights, public morals, and public order.

This may be attributed to the authors of the activities manual. They are ignoring the importance of the skills of the environment and volunteer work, despite the occupation of these skills is very important, especially in our current situations and the spread of the Coronavirus, and the crises it caused. In addition to the need for the responsible teacher to focus on his students' awareness of the importance of these skills, their relationship to their lives, and the desired benefit from them; Because the cleanliness of the environment and voluntary work is one of the main factors for preserving society and the family, which creates a feeling of safety. However, what stands in the way of the teacher and his students is that the skills of volunteer work and the preservation of the environment may need practical application outside the walls of the school in addition to work inside the school, which gives students an opportunity to take social responsibility and allow them to provide assistance, and the ability to reach constructive solutions that make them individual. They have a strong personality, they feel confident in themselves and they are able to deal with people older than them age and culture, so the process of exchanging experiences between them and the circle of knowledge and relationships widens

\section{Conclusions}

Based on the results of the study, the study recommended making use of the results of this study to review the activities guide, "the interactive curriculum for activity shares", and taking into consideration the priority of life skills. Further to coordinate between authors of activities and other institutions in the country and international organizations, which deal with life skills. Also conduct more studies on life skills that should be included in the content of the activities guide, "the interactive curriculum for activity classes" in the Ministry of Education in Jordan in and focus on other variables, given the recent application of the activities guide. Finally, the necessity to focus on life skills is related to preserving the environment and cooperative work when preparing the guide for activities and curricula.

\section{REFERENCES}

[1] Abu Sabya, M and Al-Hadidi, M., The degree to which life skills are available in the content of the sixth-grade English curriculum and the degree to which students acquire them from the viewpoint of their teachers in the capital, Amman. Educational Science Studies, 45 (3), 47-55, 2018.

[2] Abu Sabya, M and Al-Hadidi, M., The degree to which life skills are available in the content of the sixth-grade English curriculum and the degree to which students acquire them from the viewpoint of their teachers in the capital, Amman. Educational Science Studies, 45 (3), 47-55, 2018.

[3] Al-Jazi, H and Al-Rusaei, M and Saleh, R and Al-Hallilat, K., The degree of inclusion of life skills in science books for the first three grades in Jordan. Educational Science Studies, 43 (5), 41-60, 2016.

[4] Abboud, A., Life skills included in high school social studies textbooks. A research that is not published. Al-Hussein Bin Talal University, Jordan, 2016.

[5] Al-Youssef, R., Social skills, and its relationship to perceived self-efficacy and general academic achievement among a sample of middle school students in the Hayel region of Saudi Arabia in the light of a number of variables. Journal of the Islamic University for Educational and Psychological Studies, 21 (1), 327-365, 2013.

[6] Eteokleous, N., Developing Youths Cultural and Social Skills Through Asocial - Virtual Curriculum. Journal Multicultural Education and Technology, 5(3):221-238, 2011.

[7] Hayek, A., Reality of life skills development: an analytical study of the content of the Arabic language curriculum at the high level. Research that is not published. Yarmouk University, Jordan, 2014.

[8] Ige, A., The Challenges Facing Early Childhood Care. Development and Education (ECCDE) in an Era of Universal Basic Education in Nigeria, Early Childhood Education Journal, (39), 161 - 167, 2011.

[9] Sarmad, G. Habiby, S and Arvantan, M., Survey and Analysis on Content of primary Education Textbooks from Life Skills Training Point of View. Journal of Life Science and Biomedicine, 2 (5), 231 - 238, 2012.

[10] Shawish, I., The health concepts included in the science books for the sixth and seventh grades in Jordan. A research that is not published. Mu'tah University, Jordan, 2010.

[11] The Ministry of Education. (2019). Activity guide "Interactive curriculum for activity classes". Amman, Jordan,

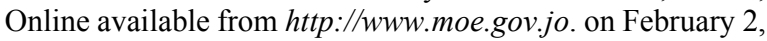
2020 .

[12] The Ministry of Education., The Ministry of Education's Strategic Plan 2018 - 2020, Amman: Jordan, 2020.

[13] Retrieved on March 10, 2020, Online available from http://www.moe.gov.jo

[14] UNICEF., Life Skills Definition of Terms. Retrieved March 2020, Online available from http://www.Unicef.org/Lifeskill s/index-7308.html

[15] Akour, A., Ala’a, B., Barakat, M., Kanj, R., Fakhouri, H. N., 
Malkawi, A., \& Musleh, G. (2020). The Impact of the COVID-19 Pandemic and Emergency Distance Teaching on the Psychological Status of University Teachers: A Cross-Sectional Study in Jordan. The American journal of tropical medicine and hygiene, 103(6), 2391-2399.

[16] Al-Zboun, M. S., Al-Zboun, M. S., \& Fakhouri, H. N. The
Role of Electronic Means in Enhancing the Intellectual Security among Students at the University of Jordan.

[17] Aladwan, F., Fakhouri, H. N., Alawamrah, A., \& Rababah, O. (2018). Students Attitudes toward Blended Learning among students of the University of Jordan. Modern Applied Science, 12(12), 217. 